\title{
On Non-traditional Design of Advertisement from the Perspective of Gender Differences
}

\author{
Yanni $\mathrm{Li}^{1,}$, , Zhijuan $\mathrm{Li}^{2}$, Jiayin $\mathrm{Li}^{3}$, Zhengpei Chen ${ }^{1}$ and Xiaoyan $\mathrm{Gu}^{1}$ \\ ${ }^{1}$ School of Foreign Languages, Changchun Institute of Technology, Jilin 130012, China \\ ${ }^{2}$ School of Foreign Languages, Changchun University, Jilin 130022, China \\ ${ }^{3}$ School of Communication, Jilin Animation Institute, Jilin 130012, China \\ aliyanni2007@163.com
}

Keywords: Gender differences, advertisement, non-traditional design, marketing.

\begin{abstract}
As a culture conveyer, advertisement can not only influence its audiences on their attitudes and behaviors, but also reflect prevailing cultural values of a society and the transformation of certain cultural norms. Therefore, more and more scholars have regarded it as an important research object in the field of economics, even in the field of sociology. This paper analyzes Chinese and English television advertisements on the basis of Social Gender Theory and Hofstede's Masculine vs. Feminine. Through the comparison between traditional and modern advertisement, conclusion can be drawn as follows: gender differences is also one of the important factors that affect the market segmentation; the non-traditional advertisement design from the perspective of gender differences just adapts to the changes of modern social cultures and economic values.
\end{abstract}

\section{Introduction}

Advertisements play a more and more important role in modern society, especially in commercial society. Everyone is under the effect of the advertisements all the time. Referring to its definition, advertisement is a kind of enforceable means by using the media's radiation to influence the public. Its purpose is to shape the new brands, increase sales, propagandize the fashion, and let the public be willing to make consumption.

If the duality of life and death is nature's number one law, said Hofstede in his Culture's Consequences, the duality of female and male is the number two law and follows very closely. In human societies of all ages and levels of complexity, this nature-given fact has been one of the very first issues with which the society had to cope in its own specific way, and which profoundly affected a multitude of societal institutions: "The sex-role system is at the core of our cultural norms"[1].

For centuries, Chinese society has set up its own value system in defining sex roles. These are considered as typical eastern cultural values that have great influence on Chinese people's perception on gender issues. With the economic development and opening up policy, China has been increasingly exposed to western cultural values especially American culture. During this process of cultural clash and integration, many traditional Chinese views toward gender differences have changed, especially the social cultural values.

Advertisement, as a cultural conveyer as well as a communication tool, has also been greatly influenced by the cultural changes. The changes in advertisement reflect in sex-role portrayals.

\section{Gender differences in Chinese and foreign cultures}

Sex-role portrayal in advertisement is an extensive topic. Researchers have great interest in sex-role portrayal due to various factors. The most important one is that marketers may use gender as a primary segmentation and that social scientists may use advertisements to examine gender stereotype in the media. 


\subsection{Studies on sex-role portrayal in foreign countries' advertisements}

Sex-role portrayal is well studied in the United States. Many researches compare American advertisement with advertisement in other cultures, such as Japanese, German, Mexican, Swedish and British culture.

One of the previous studies consisted with the present topic is Sex-role Portrayal and the Gender of Nations, conducted by Milner and Collins in 2000. Their study examines the explicit relationship between males and females from the dimension of masculinity and femininity. On Hofstede's masculinity dimension, the result is that China scores 55, while U.S. scores 62. From the study, we know that China is more feminine than America. And they also give the definitions of female countries and male countries [2]. Female countries tend to depict characters in relation with others, while male countries depict characters in independent role, the differences depicted between the two sexes is smaller in female countries' advertisements than in male countries. In practice, female in China is just like appendant of male, they do not have the equal rights in the past. That's why there are gender differences exist in the society.

Among many other scholars who study sex-role portrayal, Mary Gilly (1988) offers an analysis of sex roles in advertisement and compares content analysis findings for U.S., Australian, and Mexican television advertisements. Results reveal differences in the portrayal of the two sexes in U.S. advertisements. Australian advertisements show somewhat fewer sex role differences and Mexican advertisements show slightly more sex role differences than U.S. advertisements. Stereotypes are found in the advertisement of all three countries, but are manifested in different ways. From the analysis above, the importance of making advertisement design from the perspective of gender differences is shown very clearly.

The study conducted by Laura Milner and James Collins (2000) suggests that countries may be characterized along a continuum from masculine to feminine, to compare television advertisements from Japan, Russia, Sweden, and the United States. The result of the studies is that television advertisements from feminine countries featured more depictions of relationships between male and female characters than did masculine countries. Gender differences were expected to be fewer in feminine countries than in masculine countries.

From the above previous studies, a conclusion could be drawn that there are really gender differences exist, it mainly represents in the ways of sex-role portrayal in television advertisements.

\subsection{Studies on sex-role portrayal in Chinese advertisements}

In China, the latest research on gender images in advertisement was conducted by Chinese Academy of Social Sciences (CASS) in the year of 2005. Capital Women Journalists Association released the results of the study before last year's International Women's Day on March 8th (China Daily, 2006). The result shows that most Chinese TV advertisements depict women, especially young women, as avid consumer or housewives without a distinctive expertise, profession or career. In the advertisements, young and mostly pretty women "get many close-ups, appearing to flaunt their sex appeal as the advertisement zooms in on their faces, hair, lips, and svelte, voluptuous figures." (China Daily). In contrast, men in the advertisement are mostly portrayed as successful professionals: doctors, professors or engineers. Meanwhile, in a family setting, more men appear to be enjoying and idling time away, while more women do the housework.

Other scholars, Hong Cheng and Guofang Wan (2005) studied male and female images portrayed in Chinese subway advertisements and found many gender stereotypes. For example, men were more frequently portrayed than women in occupational roles, whereas women were more often shown than men in fulfilling family duties in non-occupational roles. Women were also found far more often than men in seductive dress and in a young age group. 


\section{Comparison between English and Chinese Advertisements}

In modern society, everyone is under the effect of the advertisements all the time [3]. You may be bored with them sometimes, but the important roles that advertisements play when cultural factors are taken into consideration cannot be ignored. Now, let's look at it from the concept of advertisement.

\subsection{Traditional values on sex roles}

Traditional Chinese society was constituted by unequal relationships developed over thousands of years in which the male element was dominant (Leung, 2003). A key element of this system was rigid hierarchy of authority based on the so-called, or "five cardinal relations", composed of ruler-ruled, father-son, elder brother-younger brother, husband-wife and friend-friend (male friends). Established by Confucius around $500 \mathrm{BC}$, it clearly states that the unequal relationship between people is the basis of a stable society.

As the basic unit consisting of the society, patriarchal family system was dominated by the older generations and power was invested in the male head of the household. Women were seen as temporary members of their own families and had no rights to property or inheritance. When a daughter married, she had to leave her own family and join her husband's household and the family norms remained her norms for the rest of her life.

Confucian ethics accepted the subjugation of women to men as natural and proper because women were generally regarded as unworthy or incapable of education. There were "Three Obediences" governing a woman's behavior: as an unmarried girl she must obey her father and brothers; as a married woman she must obey her husband; and as a widow she must obey her adult sons. According to Leung (2003), "women were not in any way in control of their destiny and were severely oppressed under the social and moral hierarchy of sexual relations in tradition China." A Chinese woman's identity was defined in terms of her unquestioning obedience and deference to the authority of her husband's household at marriage and her eternal attachment to it. The traditional Confucian gender concepts of "virtuous wife and good mother" and "exalting males and demeaning females" were fundamental principles to assess a woman's behavior and aspirations, and her status relative to that of men (ibid).

It was not until the May Fourth Movement (1915-1921), the first women's movement in China which was strongly influenced by western thought, that women's rights of education, romantic love and individual emancipation were freed from patriarchal authority. While in America, whenever we think about any of its values we cannot forget individualism, "all values, rights, and duties originate in individuals" (Samovar and Porter, 2001:55). The value of individualism is so commanding that other imperative American values spring from individualism. Most Americans believe in each person's separate identity, which should be recognized and reinforced, no matter male or female.

Gender equality has always been seeking its own voice in American history. Equality, closely related to individualism, is emphasized in everything from government to social relationships. With regard to the issue of sex roles, as Tocqueville phrased it, Americans did not believe that the two sexes should "perform the same offices, but they show an equal regard for both of their respective parts; and though their lot is different, they consider both of them as being of equal value" (cited by Degler, 1984: 458). In the early seventeenth century, both husband and wife of an American family had to work to wrest a living. Within a family the work done was sharply defined by gender. Though the jobs may change over time, the division of labor by gender has continued well until the opening of the twentieth century.

When the twentieth century began, all different varieties of American families shared one characteristic: the wife did not work outside the home. To early-twentieth-century Americans, as for nineteenth-century people, a working wife was a sign that a husband was not able to support a family or that he was crippled or otherwise incapacitated. The proportion of married women who worked for wages in 1900 was less than 7 percent, though today the pattern is almost reversed [4]. 
From this one could see that traditionally women enjoyed a position central to a family, the principles prevailing at that time is women's attachment to and dependent on men, as well as men's dominance and authority over women within the family.

\subsection{Cases of traditional advertisement design}

From the above analysis, everyone knows that there is no gender equality between male and female in the past, and this kind of social culture also embodies in the design of advertisements. Therefore, in traditional way, the design of advertisements mainly reflects on the expectations of males toward females, as we referred to before.

For example, a cosmetic advertisement is the typical example. On the right of the picture in this advertisement, there is a man neatly dressed, who, as we look at, is a successful person from his appearance. With a magnifying glass, he looks at the cheek of the girl on the left of the picture carefully. Then he finds that there is no speckle or scar in her face any more. But ten days ago, the situation was greatly different. And now, because of her beautiful face, the girl in the picture is smiling confidently, no matter in which method the man tries in order to find disadvantages on her face. The picture tells us that the happiness of females is being liked by males, that is to say, females should try their best to win the males' favor, but the necessary precondition to get to this aim is that you should be young, beautiful and full of energy. The piece of advertisement tells us that beauty is equal to happiness for females. But this kind of happiness has nothing to do with the success in her own career, and it depends only on her appearance.

Take another classical one as the example. It is a sock advertisement with the brand of Langsha. On the right of the picture, there is a female who has the model stature, and full of charm. She is addressed in the suspenders skirt with two forks on her waist, she looks to the left gracefully, and makes an extremely standard model gesture, especially highlights her own sexy hip department, and the slender jade leg, as well as a pair of transparent sock on her jade leg. Who does this female demonstrates her sexy for? Right, on the left hand of the original picture, there stands a man in extremely neat clothing that is very popular in current clothing market (so-called "the Successful Figure "). He raises his right hand high to the forehead, and looks up to that female who is on his right, the appearance is completely as looking at the scenery. In this kind of typical case, the relation between to look and to be looked in this advertisement is a kind of main body vs. object, the control vs. be controlled [5]. The masculine in this advertisement is in the absolute initiative position, but the female be looked as scenery is a passive guest.

\section{Summary}

In the extremely competitive marketplace, marketers wish their products could draw more and more consumers' attention. And in modern society, as the development of the advanced technology, advertisement in television has been the most often used instrument. According to the research of the similar previous studies conducted by famous professors in this field, we know that men and women, as the direct target of the advertisement, had been mainly studied, but the designers often thought that certain kind of products should be positioned for certain gender. Because of this, fixed design of advertisement, even fixed design of particular products has occurred. The direct effect of this phenomenon is that the sales volume of the products in this kind of advertisement has decreased.

\section{Acknowledgements}

The authors would like to give their thanks to The Education Department of Jilin Province (NO. 2015-201) and Jilin Association for Higher Education (JGJX2015C71) for their financial and technical support. 


\section{References}

[1]. Degler, Carl N. Out of Our Past, Forces that Shaped Modern America $3^{\text {rd }}$ ed. New York: Harper \& Row, 1984, 10-14.

[2]. Rofel, L. Liberation Nostalgia and a Yearning for Modernity. Engendering China. Cambridge, MA: Harvard University Press, 1994, p50-54.

[3]. Li Yanni, Li Jiayin, Lv Zheng, Li Tianyu and Tang Yanling. Study of Online Accounts Safety and Online Payments by Smart Phones. Journal of Software Engineering, 2015 9(4), p877-885

[4]. Milner, Laura. and Collins, James. Sex-role Portrayals and Gender of the Nations. .Journal of Advertisement, 2000, p26-30.

[5]. Samovar, Larry A. and Porter, Richard E. Communication between Cultures, $5^{\text {th }}$ Ed. Beijing: Peking University Press, 2001, p103-108. 